\title{
Elementos para uma Sociologia das Relações Internacionais: o campo dos diplomatas e o Estado como metacampo
}

\author{
Elements for a Sociology of International Relations: \\ the field of diplomats and the state as metafield
}

\section{Leandro Garcez Targa}

\begin{abstract}
Resumo As metodologias de pesquisa que analisam as relações sociais em âmbito local podem ser as mesmas que pensam as relações sociais em âmbito global. Este princípio epistemológico é a base para o entendimento (e para a proposta de superação) das lacunas geradas pela produção de conhecimento das Relações Internacionais, disciplina que reivindica, com sucesso, o monopólio da análise sobre "o internacional" no campo acadêmico. É a partir desta ideia que o presente artigo se propõe a apresentar elementos que contribuam para a construção e consolidação de uma "sociologia das relações internacionais”. Este texto é um fragmento de tese de doutorado recentemente finalizada sobre o campo dos diplomatas brasileiros. Apresentamos aqui a definição bourdieusiana de Estado como metacampo e um esboço da definição de campo das relações internacionais. A partir disso, sugerimos um exercício inicial para pensar o que pode ser uma sociologia das relações internacionais, propondo assim a abertura para futuras pesquisas.
\end{abstract}

Palavras-chave Sociologia das relações internacionais, sociologia de Bourdieu, Estado como metacampo, campo das relações internacionais, campo dos diplomatas.

Abstract The research methodologies that analyze social relations at the local level may be the same as those that think the social relations at the global level. This epistemological principle is the basis for understanding (and for the proposal to overcome) the gaps generated by the knowledge production of International Relations, discipline which successfully claims the monopoly of analysis on "the international" in the academic field. It is from this idea that the present article intends to present elements that contribute to the construction and consolidation of a "sociology of international relations". This text is a fragment of the recently completed doctoral thesis on the field of Brazilian diplomats. Here we present the Bourdieusian definition

a Doutor pelo Programa de Pós-Graduação em Ciência Política da Universidade Federal de São Carlos (UFSCar). Contato: leandro.g.targa@gmail.com. 
of State as a metafield and the sketch of the definition of the field of international relations. From this, we suggest an initial exercise to think what can be a sociology of international relations, thus proposing the opening for future research.

Keywords Sociology of international relations, Sociology of Bourdieu, State as metafield, field of International Relations, field of diplomats.

\section{INTRODUÇÃO}

A partir da perspectiva teórica de Pierre Bourdieu, desenvolvemos uma pesquisa que teve como objetivo geral realizar um estudo relacional sobre a ação dos diplomatas brasileiros no período de governo dos ex-presidentes Fernando Henrique Cardoso (FHC) e Luiz Inácio Lula da Silva (Lula), ou seja, entre os anos de 1995 e 2010. A definição do recorte temporal já identifica o principal objetivo específico da pesquisa: entender a dinâmica de ação dos diplomatas a partir de sua relação com o processo de alternância entre os dois governos citados. Ainda, definimos, como estratégia de pesquisa, fazer essa análise a partir de um "jogo jogado" pelos diplomatas, as ações relacionadas ao processo de seleção e formação de novos diplomatas. Isso nos levou ao Instituto Rio Branco (IRBr), instituição ligada ao Ministério das Relações Exteriores (MRE) que detém o monopólio de seleção e formação dos diplomatas brasileiros. ${ }^{1}$

Para desenvolver a pesquisa, uma das bases e principais referências teóricas na perspectiva da teoria bourdiesiana que utilizamos foi a definição do autor acerca do conceito de Estado. Entendemos que a definição de Bourdieu de Estado inaugura uma perspectiva nova para o que comumente denominamos de análises das "relações internacionais". Esta nova perspectiva ainda é pouco explorada quando se trata de estudos sobre os diplomatas, especialmente os brasileiros. Por isso, na medida em que fomos desenvolvendo a pesquisa, percebemos que aliar a teoria bourdiesiana ao estudo de diplomatas significava se valer de instrumental teórico não convencional para a análise de um objeto de pesquisa reivindicado principalmente pela disciplina das Relações Internacionais.

Esta área de produção de conhecimento acadêmico vem crescendo de maneira rápida e se fortalecendo nas últimas décadas, reivindicando o monopólio da expli-

1 Este artigo apresenta uma parte de minha tese de doutorado intitulada "Os diplomatas brasileiros sob a perspectiva relacional: o campo dos diplomatas e o campo político" (TARGA, 2017). Agradeço à Fapesp pelo financiamento desta pesquisa e aos integrantes do Núcleo de Estudos de Sociologia Econômica e das Finanças (NESEFi-UFSCar), em especial ao professor Roberto Grün, orientador deste trabalho, por todo suporte e apoio para realização desta pesquisa. Agradeço também à Professora Maria Caramez Carlotto a leitura atenta e as importantes contribuições a este artigo. 
cação sobre “o internacional”. Porém, entendemos que as já tradicionais teorias das Relações Internacionais apresentam limitações em suas análises que podem ser superadas pela sociologia bourdiesiana. Partimos do princípio de que as mesmas metodologias de pesquisa que analisam as relações sociais em um âmbito local podem ser utilizadas para pensar relações sociais mundializadas (SimÉANT, 2015). Por isso, começamos a entrever a possibilidade de que nossa pesquisa poderia apresentar elementos que contribuam para o desenvolvimento de uma "sociologia das relações internacionais", a partir do ponto de vista da análise do campo dos diplomatas.

A metodologia de análise relacional de Bourdieu sobre o mundo social conceitualiza os indivíduos como "agentes" na medida em que parte do princípio de que estes produzem e, ao mesmo tempo, são produzidos pelos espaços sociais - as estruturas sociais - das quais fazem parte. Estes indivíduos (a partir de agora denominados neste trabalho como agentes) agem em espaços relacionais entendidos não como instituições, mas como "campos". Estes agentes entram em disputas para impor uns aos outros, principalmente por meio de violência simbólica, os princípios de visão e divisão do mundo social que possuem, o que significa reconhecer que eles lutam para exercer a dominação simbólica no campo do qual fazem parte. Fazem isso através do uso de seus recursos materiais e simbólicos, que Bourdieu intitula “capitais”. Estas disputas influenciam, portanto, a constituição de elementos do campo dos agentes e são a base da sua ação social. São as estruturas estruturadas inculcadas nos agentes que possuem o potencial de serem estruturas estruturantes do campo, ou seja, o "habitus".

Estes e outros instrumentos conceituais da teoria bourdiesiana, associados à metodologia estatística de análise de dados denominada Análise Geométrica de Dados (AGD), pavimentaram o caminho escolhido para desenvolvermos a pesquisa que, portanto, pode ser classificada como um exercício de sociologia relacional, sociologia da reprodução social ou sociologia bourdiesiana. Dadas as dimensões deste artigo, esses elementos da teoria bourdiesiana não poderão ser melhor definidos e explicitados aqui. Contudo, no decorrer da pesquisa já realizada (TARGA, 2017), estes elementos foram testados e aplicados empiricamente. Segundo o arcabouço teórico adotado, estes elementos não podem ser tomados como conceitos estritamente teóricos de análise do mundo social. Uma condição para a adoção da teoria bourdiesiana em pesquisas acadêmicas é a de que o pesquisador encontre nesses conceitos as pré-noções teóricas necessárias para o desenho da pesquisa, conceitos que, portanto, apenas terão validade a partir da pesquisa empírica, num exercício de adaptação da teoria à empiria e não o contrário: 
Gostaria de submeter a uma elaboração e a um controle metódicos o sistema de conceitos que guiou minhas pesquisas e que outorga coerência teórica a trabalhos dedicados a objetos muito diversos na aparência, sem, no entanto, ceder à tentação de transformá-los em axiomas prematuramente, o que poderia tirar desse corpo de conceitos produzido para e pela prática científica a margem de incerteza que constitui frequentemente a virtude heurística (BouRdIEu, 2003b, p. 38).

Com esse arcabouço teórico, partimos, então, do pressuposto de que os diplomatas são agentes do campo dos diplomatas, o que significa dizer que não constituem um grupo homogêneo quanto às suas ações e formas de pensar. São agentes que compartilham o mesmo habitus do campo dos diplomatas e que, por isso, estão em constante disputa pela dominação simbólica das ações que conduzem este mesmo campo. Contudo, esse pressuposto, como exigência do arcabouço teórico citado anteriormente, foi testado durante a pesquisa empírica da mesma forma que nossa hipótese inicial de trabalho: a dinâmica de disputas internas do campo, apesar de ter um alto grau de autonomia, principalmente no que se refere ao processo de seleção e treinamento de novos diplomatas, apresenta a interferência de um fator externo importante para entendermos a sua lógica de funcionamento, qual seja, a ação do campo político.

Utilizamos a metodologia da análise prosopográfica dos agentes do campo, associada às ferramentas de análise estatística da Análise de Correspondência Múltipla (ACM) como maneira de realização do estudo proposto. Entendemos que o método estatístico da AGD (da qual a ACM é uma das componentes) se mostra uma importante ferramenta de auxílio a pesquisas na perspectiva de estudos bourdiesianos. Esse instrumento de pesquisa ajuda o pesquisador a formular análises sobre as ações dos agentes do campo de maneira tanto multidimensional quanto relacional, trabalhando, ao mesmo tempo, o agente (e seus capitais), o campo (a estrutura) e o elemento que os une, o habitus. O uso da AGD é a forma de, na prática, o pesquisador conseguir combinar a construção objetiva de análise quantitativa de dados e informações estatísticas com a noção teórica de campo inserido em um espaço social geral.

Vários são os estudos que apontam para a independência e autonomia da ação dos diplomatas em relação ao "jogo jogado" no campo político, trazendo a ideia de "insulamento do Itamaraty" sobre a formulação e execução da política externa brasileira (Oliveira, 2011; Neves, 2003; Figueira, 2010a; Figueira, 2010b; FARIA, 2008, entre outros). Porém, a pesquisa mostrou que a alternância de poder no executivo federal no período focado pelos estudos representou interferência no 
campo dos diplomatas. As eleições de 2002 representaram a ascensão do "baixo clero" do campo político brasileiro e, consequentemente, uma redefinição da ordem simbólica no campo do poder (GRÜN, 2012). Coube a este trabalho uma avaliação do impacto desta redefinição em uma parte do campo do poder, o campo dos diplomatas. Mostramos ainda que o campo dos diplomatas é parte integrante do campo político, e que a ideia de "insulamento do Itamaraty" é uma das noções morais do campo que foram objetivadas na pesquisa, componente do processo de construção de autonomia dos agentes em relação aos "de fora" do campo. Entendemos também que esta estratégia do campo dos diplomatas vem sendo bem sucedida na medida em que o "insulamento do Itamaraty" é tema presente em muitos trabalhos acadêmicos e jornalísticos, quase sempre um conceito inquestionado, mostrando que é grande a influência da lógica de funcionamento do campo dos diplomatas sob outros campos, como o acadêmico e o jornalístico.

Procuramos utilizar como referências bibliográficas trabalhos que apresentam abordagens conceitualmente diferente, podemos dizer contra hegemônicas, dos diplomatas e de outros objetos de pesquisa tradicionalmente vinculados à disciplina das Relações Internacionais. Para isso, encontramos importantes referências estrangeiras (Bourdieu, 2002, Dezalay e Garth, 2002; SimÉant, 2015; SAPiro, 2013; Bigo, 2011; Adler-Nissen, 2011; Leander, 2011; Merand, 2008; Sabine, 2008; PouponneAu, 2015), das quais algumas são abordagens internacionalistas que utilizam Bourdieu em suas pesquisas. No Brasil, encontramos principalmente duas autoras que apresentam um olhar sobre os diplomatas diferente dos internacionalistas, Gobo (2016) e Moura (2000, 2006 e 2007). Há outras pesquisas brasileiras que também apresentam pontos de vista alternativos aos das Relações Internacionais sobre os diplomatas, como as de Monteiro (2007), Batista (2010), Lima (2005), Oliveira (2011), Góes Filho (2003), Tomass (2001), Balbino (2005) e Silva (2005). Porém nenhum desses trabalhos nacionais se apresenta com o propósito que estamos denominando de "sociologia das relações internacionais". Isso mostra que essa perspectiva de pesquisa é um campo ainda a ser explorado, já que o arcabouço teórico bourdiesiano - principalmente a noção de Estado como metacampo - é pouco utilizado pelos pesquisadores que procuram superar os limites das tradicionais abordagens das Relações Internacionais para estudar relações sociais internacionalizadas.

Neste texto, procuramos destacar os elementos que entendemos que podem contribuir para o debate acerca da produção de conhecimento sobre "o internacional" em pesquisas nas Ciências Sociais, especificamente o desenvolvimento da sociologia das relações internacionais. Para isso, abordaremos aqui principalmente 
a noção de Estado na teoria bourdiesiana. Como já mencionado, é a partir desta noção que vislumbramos a maior contribuição desta maneira contraintuitiva de estudo sobre temas que envolvem relações sociais em âmbitos internacionalizados. Além desta noção de Estado, apontaremos também para elementos da pesquisa sobre os diplomatas que a caracterizam como um estudo sobre o campo dos diplomatas, agentes que são produto da relação entre os Estados e o processo de normatização das relações sociais em âmbitos internacionalizados.

\section{OUTRA METODOLOGIA PARA ANALISAR "O INTERNACIONAL"}

As relações comerciais e políticas do Estado brasileiro com outros países e órgãos internacionais vêm sendo objeto de estudos de trabalhos acadêmicos ligados principalmente às áreas das Ciências Sociais, Direito, Relações Internacionais e Economia, sobretudo depois da metade dos anos 1970 (Miyamoto, 1999; Figueira, 2010a; FARIA, 2008; Gobo, 2010; Cervo e Bueno, 2002). Os recentes estudos sobre a política externa brasileira chamam a atenção, por um lado, para o contexto internacional de redefinição da ordem política e econômica mundial com a atenuação da polarização leste/oeste no período conhecido como "guerra fria" e, por outro, para o contexto nacional dos recentes dezesseis anos de mandato dos ex-presidentes FHC e Lula, os quais representam a alternância dos dois principais partidos políticos em disputa pelo poder executivo nacional desde o curto período de reabertura política do país e promulgação da Constituição de 1988 (SALES, 2007).

Contudo, observamos ainda poucos trabalhos sobre a política externa e o campo de ação dos diplomatas brasileiros a partir da perspectiva teórica da sociologia em geral, e de Pierre Bourdieu, em particular. Existem alguns trabalhos com esta temática e perspectiva teórica, porém sobre o contexto de outros países, poucos sobre o contexto brasileiro. Entendemos que as ferramentas teóricas de pesquisa de Bourdieu (como campo e habitus) podem ser usadas para analisar precisamente dinâmicas sociais contemporâneas que envolvam, por exemplo, a discussão da relação entre o campo político, o campo do poder e o campo dos diplomatas.

Adler-Nissen (2011), Bigo (2011) e Leander (2011) concordam quanto aos avanços que a utilização da perspectiva teórica bourdiesiana pode trazer às análises sobre relações internacionais. A partir da perspectiva de pesquisa bourdiesiana é possível diagnosticar um dos principais problemas dos estudos internacionalistas contemporâneos: a relação fraca entre teoria, metodologia e pesquisa empírica. Os atuais trabalhos de relações internacionais têm sido organizados a partir da oposição entre trabalhos empiristas-objetivistas (os dominantes no campo) versus construtivistas, que negligenciam o mais básico conhecimento de como práticas 
sociais são construídas para além das vontades racionalizadas dos indivíduos (BıGO, 2011). Um olhar bourdiesiano sobre "o internacional” vira as teorias tradicionais de relações internacionais de cabeça para baixo (AdLER-Nissen, 2011). Por exemplo, enquanto os neorrealistas afirmam que o sistema internacional é anárquico, um olhar bourdiesiano dirá que é hierarquizado. Outro exemplo, a Escola Inglesa defende que "Estados párias e Estados falidos" podem ser vistos como estando fora da sociedade internacional, relegados ao mais abstrato sistema internacional, com interações menos densas. Porém, uma abordagem bourdiesiana argumentaria que processos de exclusão são intrínsecos a sociedades internacionais. Estados só se tornam "párias" através de sua interação intensa com o resto do mundo. Afirma Adler-Nissen que, embora isso possa parecer um argumento construtivista sobre características sociais de políticas internacionais, a teoria bourdiesiana não faz parte da corrente construtivista na teoria das relações internacionais. Anarquia não é o que o Estado faz porque o campo internacional já está estruturado pela própria relação histórica que os Estados possuem. A marginalização de alguns Estados, grupos ou indivíduos pode ser explicada pelas mudanças de padrões de formas culturais e simbólicas de dominação e de competição por poder e prestígio (ADLER-NisSEN, 2011).

\section{A IMPORTÂNCIA DA NOÇÃO DE CAMPO APLICADA À DEFINIÇÃO DE ESTADO PARA ESTUDAR AS RELAÇÕES SOCIAIS INTERNACIONALIZADAS}

A inspiração para trabalhos que utilizam a perspectiva bourdiesiana em análises sobre relações sociais internacionalizadas começa pela compreensão da ideia de Estado como campo (Bigo, 2011; AdLER-Nissen, 2011). ${ }^{2}$ Para entendermos a noção de campo aplicada ao Estado, principalmente para se entender como o Estado é um campo peculiar se comparado a outros campos sociais, é necessário levar em consideração o alerta que Bourdieu faz quando se pretende fazer uma sociologia do Estado. Pensar o Estado é aplicar categorizações ao Estado que são produzidas pelo próprio Estado, principalmente através da escola. O Estado

2 Apesar de tratar indiretamente do Estado em boa parte de sua obra, foi apenas no começo dos anos 1980 que a palavra "Estado" apareceu nos escritos acadêmicos de Bourdieu. Em 1984, em "Homo academicus", o autor definiu Estado como a "instância oficial, reconhecida como legítima, isto é, como detentora do monopólio da violência simbólica legítima”. Mais tarde, em 1989, publicou "A nobreza de Estado", quando assumiu de vez "o Estado" como conceito em sua obra. Em 1993 publicou "A miséria do mundo", quando o conceito foi mais frequentemente utilizado (BOURDIEU, 2014, p. 490). Dez anos após sua morte, em 2012, foi lançado o livro "Sobre o Estado: curso no Collège de France (1989-92)", coletânea de transcrições de aulas de Bourdieu sobre este tema, e que traz a linha de pensamento do autor sobre a gênese e formação do "metacampo Estado" e suas implicações na vida social. 
"produz e impõe as categorias de pensamento que utilizamos espontaneamente a todas as coisas do mundo, inclusive ao próprio Estado" (BouRdiEu, 2011a). Estamos sempre correndo o risco de sermos pensados por um Estado que acreditamos pensar. O Estado se pensa através daqueles que se esforçam para pensá-lo. Para analisar o Estado, portanto, é necessário se colocar em questão todos os pressupostos e todas as pré-construções inscritas na realidade social que se trata de analisar, e no próprio pensamento dos analistas desta realidade.

O Estado é um grande produtor simbólico: os agentes do Estado são produtores de "problemas sociais", os quais, muitas vezes, as ciências sociais ratificam, transformando-os em problemas sociológicos. Bourdieu vai buscar em Durkheim e Hegel a noção de que o Estado funciona como uma burocracia dotada de representação do interesse coletivo e universal. $\mathrm{O}$ autor indica que grande parte dos estudos sobre o Estado reproduzem o Estado e o constroem, sobretudo os estudos dos juristas dos séculos XVI e XVII. Para as Ciências Sociais terem se construído ao longo da história como independentes das pressões e demandas sociais (o que lhes garantiu o caminho em direção à "cientificidade”) elas precisaram do Estado. Mas, por isso, correm o risco constante de serem submissas ao próprio Estado e suas demandas.

"O Estado é um x (a ser determinado) que reivindica com sucesso o monopólio do uso legitimo da violência física e simbólica em um território determinado e sobre o conjunto da população correspondente" (Bourdieu, 2011a, p. 97, grifo meu). Bourdieu recorre a Max Weber ${ }^{3}$ em uma das definições mais consagradas e amplamente utilizadas em pesquisas acadêmicas sobre o Estado no intuito de chamar a atenção para o fato de que a especificidade do Estado não é a acumulação de violência física legítima mas, antes, está posta na monopolização da legítima violência simbólica.

O Estado é uma instituição que se encarna nas estruturas sociais e mentais da população correspondente, dando a aparência de "natural” às ações resultantes de longos e complexos processos e dinâmicas de disputas. Um exemplo disso é o das "reformas ortográficas" que acontecem de tempos em tempos em vários países: mudanças promovidas pelo Estado a uma maneira das pessoas se relacionarem com a linguagem do dia a dia. Nestes momentos, não é raro encontrar opiniões de críticos ortodoxos da ortografia que classificam as mudanças impostas pelo Estado como um atentado à maneira "natural" de se relacionar com a linguagem. Porém, suas críticas não levam em conta que, em algum tempo passado, esta maneira que 
classificam como "natural" de se relacionar com a linguagem foi formulada pelo próprio Estado. É uma ação proveniente do Estado sendo tratada como "natural" pelos indivíduos. "As coisas da cultura, particularmente as divisões e hierarquias sociais a elas associadas, são constituídas como natureza pela ação do Estado que, instituindo-as ao mesmo tempo nas coisas e nos espíritos, confere todas as aparências do natural a um arbitrário cultural" (BouRdieu, 2011a, p. 95). Neste ponto, entendemos o Estado como um instrumento de consolidação de características culturais no dia a dia dos indivíduos, transformando em "natural" atitudes arbitrárias, fruto de disputas historicamente contextualizadas. Em outras palavras, o Estado tem o poder de conferir o status de "natural" às visões e divisões de mundo, hierarquias sociais construídas historicamente através de conflitos e lutas entre agentes.

O Estado é o resultado de um processo de concentração de diferentes tipos de capital: capital da força física ou instrumentos de coerção, capital econômico, capital de informação, capital simbólico. Esta concentração transforma o Estado no produtor de uma espécie específica de capital, um metacapital, o capital propriamente de Estado, com poder sobre os outros tipos de capitais e seus detentores. Isso permite que o Estado exerça um poder sobre os diversos campos sociais e as diferentes espécies de capitais. Por isso, o funcionamento do Estado está intrinsicamente relacionado à dinâmica de funcionamento do campo do poder: "espaço de jogo no interior do qual os detentores de capital (de diferentes tipos) lutam particularmente pelo poder sobre o Estado, isto é, sobre o capital estatal que assegura o poder sobre os diferentes tipos de capital e sobre sua reprodução" (Bourdieu, 2011a).

Entender o Estado como campo significa entender, como estratégia de pesquisa, a necessidade da reconstrução da gênese do Estado, momento que pode trazer à tona os processos que determinaram os rumos do Estado, ou a ação do Estado. Para isso, Bourdieu retoma estudos de Tilly, Weber e Elias sobre o vínculo da gênese dos Estados pela via do domínio da violência física, em um primeiro momento, e do capital econômico, pela cobrança de impostos para se fazer a guerra, em um segundo momento. Esse processo, aos poucos, transformou o capital econômico em capital simbólico do príncipe (haja vista a resistência que se relata ao pagamento dos impostos, seguida de sanções do Estado aos cidadãos). Paulatinamente, os impostos deixaram de se tornar atos de extorsão do príncipe para se tornarem necessários para a coletividade. Esta foi a transformação do Estado dinástico em Estado "impessoal", que corresponde ao nascimento do nacionalismo ou do valor unitário de território nacional. 
Contudo, as fraudes fiscais mostram que a legitimidade dos impostos não é dada. O domínio do capital da força física e do capital econômico se transforma em domínio do capital de informação, que é uma dimensão do capital cultural. $\mathrm{O}$ Estado concentra as informações, as analisa e as redistribui, realiza uma unificação teórica baseada no recenseamento e na estatística, seja pela contabilidade nacional, seja pela objetivação cartográfica do território nacional, seja pelo uso da escrita e acumulação do conhecimento através dos arquivos do Estado. O Estado contribui para a unificação do mercado cultural ao unificar os códigos (linguísticos, jurídicos, métricos) e homogeneizar as formas de comunicação burocrática e oficial. Desta forma, o Estado molda as estruturas mentais, e impõe princípios de divisão comuns, ou seja, formas de pensar que estão para o "pensamento culto" assim como as formas primitivas de classificação de Durkheim e Mauss estão para o "pensamento selvagem" (BouRdieu, 2011a). Isso contribui para classificarmos o Estado comumente como identidade nacional, uma verdadeira religião cívica destaque para o papel da escola e a universalização da educação, no século XIX, no processo de domínio simbólico do Estado.

A cultura é prática tão profunda dos símbolos patrióticos que todo questionamento crítico sobre suas funções e seu funcionamento tende a ser percebido como traição e sacrilégio. A unificação cultural e linguística é acompanhada pela imposição da língua e da cultura dominantes e pela rejeição de todas as outras. Contudo, a exigência da universalização não é acompanhada pela universalização do acesso aos meios de satisfazê-la, favorecendo tanto a monopolização do universal por alguns quanto a exclusão de todos os outros, de certa forma mutilados de sua "humanidade cívica". Desta forma, o Estado é também definido como sendo o espaço social legítimo que concentra capital simbólico, com potencial de distribuição deste pelos agentes a partir do resultado das disputas entre eles.

A ação do Estado está associada à concentração de capital simbólico de autoridade reconhecida. Capital simbólico é a forma que todo e qualquer tipo de capital - social, econômico, físico - assume quando é percebido pelos agentes sociais ao ponto de poderem entendê-lo (percebê-lo) e reconhecê-lo, atribuindo-lhes valor (Bourdieu, 2011a). Neste ponto, o Estado é o lugar por excelência da concentração e do exercício do poder simbólico, pois é ele que dispõe de meios para impor e inculcar princípios duráveis de visão e divisão de acordo com suas próprias estruturas. O capital jurídico é a forma objetivada e codificada do capital simbólico. A gênese do Estado passa pela concentração do capital simbólico antes difuso, apoiado apenas em um reconhecimento coletivo, de títulos de nobreza, por 
exemplo, para um capital simbólico objetivado, codificado, delegado e garantido pelo Estado, portanto, burocratizado.

O reconhecimento da legitimidade do Estado não é um ato consciente e esclarecido individual. $\mathrm{O}$ reconhecimento é enraizado nas estruturas incorporadas pelo indivíduo (habitus), tornadas inconscientes como, por exemplo, as que organizam os ritmos temporais, calendários e divisão das horas. É este fato que explica a facilidade com que os dominantes impõem sua dominação. Nesse sentido, dominar o Estado significa a possibilidade de impor a dominação simbólica sobre práticas sociais enraizadas. A legitimidade do Estado se constrói a partir de tomadas de opinião. O Estado não tem a necessidade de dar ordens, ou de exercer coerção física para produzir um mundo social ordenado, basta manter a produção de estruturas cognitivas incorporadas que estejam em concordância com estruturas objetivas que produzam a submissão à ordem estabelecida. Portanto, para entender a dimensão simbólica do efeito do Estado (principalmente o efeito universal), é preciso entender o funcionamento específico do microcosmo burocrático.

Desta forma, Bourdieu associa como indissociáveis a construção do monopólio estatal da violência física e simbólica e a dinâmica do campo de lutas pelo monopólio das vantagens vinculadas a este monopólio. O domínio do capital estatal pela "nobreza de Estado" representa o domínio da universalização que o Estado promove através do monopólio que exerce. Nesse sentido, as disputas internas ao campo do poder, ou seja, as disputas em torno do controle simbólico do Estado, pelo controle do capital estatal, significam dominar os mecanismos de imposição simbólica sobre as práticas sociais amplamente enraizadas por todos os agentes que estão sob a influência daquele Estado. Bourdieu usa a metáfora do metacampo para descrever o Estado como um lócus onde diferentes elites (ou grupos dirigentes) provenientes de diferentes campos sociais confluem para disputar o controle do acesso às regras e práticas de conversões de capitais e elas mesmas converterem as diferentes formas de capital que acumularam em capital simbólico de dominação. O Estado deve ser visto então como um campo criador e monopolizador de violência simbólica.

A relação entre as instituições, os espaços sociais, os campos, que formam o Estado e o efeito do Estado como metacampo e detentor de um metacapital podem ser entendidos a partir da ideia de que o Estado é o produtor e, ao mesmo tempo produto, de um processo dialético: de um lado, os campos relativamente autônomos nos quais as sociedades estão organizadas e, de outro, a emergência de um espaço que concentra os poderes sobre esses últimos e em que as lutas são lutas entre os próprios campos. "A construção do Estado como metacampo, como 
poder de construção de todos os campos, [passa pela] construção de cada um dos campos. (...) constrói-se o Estado como instância metacampo contribuindo para a constituição dos campos" (Bourdieu, 2014, p. 271). Portanto, para entender a construção e condução do Estado se faz necessário entender a construção e condução dos campos - mais ou menos autônomos - que formam este Estado, sem deixar de ter em perspectiva que estes subcampos também são conduzidos e construídos por este Estado na forma de metacampo.

Grande parte das pesquisas tradicionalmente vinculadas à produção de conhecimento hegemônico da disciplina de Relações Internacionais rejeita a ideia de que o Estado não é um ator. Contudo, a sociologia de Bourdieu, entendendo o Estado como campo (metacampo), passa a pesquisar sobre quem atua dentro do metacampo Estado, por exemplo, qual é a elite dominante, como se configura essa disputa (Bigo, 2011; AdLer-Nissen, 2011). O Estado é o resultado de lutas, por isso, não é um campo composto por agentes homogêneo e unitários, ou seja, para essa perspectiva, o Estado não é uma entidade singular.

\section{UM ESBOÇO DE DEFINIÇÃO DO CAMPO DAS RELAÇÕES INTERNACIONAIS}

A partir da noção de campo aplicada à definição de Estado, internacionalistas repensaram suas definições de pesquisa e propuseram novas questões para análise. Entendendo que o Estado é coerentemente moldado de acordo com os subcampos sociais que os forma, Bigo (2011) lembra ainda que as lógicas liberais e capitalistas promovem trocas transnacionais de poder simbólico com a criação de valores internacionais e internacionalizados que interferem também na dinâmica dos Estados nacionais, ou seja, dos campos do poder local, especialmente com a "circulação internacional de ideias" (Bourdieu E WACQUANT, 2001; BourdiEU, 2002). A partir disso, Bigo (2011) levanta questões como: existe um campo do poder global? E, se existir, de que forma este interfere nos campos do poder locais para a disputa e condução dos Estados? Este campo do poder global possui o formato de cada campo local ou molda o campo local? Qual a fronteira entre o local e o global na formação do campo do poder que disputam os Estados?

Adler-Nissen (2011) descreve as relações internacionais entre Estados a partir da noção de campo ao afirmar que, no encontro e relação entre Estados, um único Estado não consegue estruturar o significado das interações sociais feitas. Desta forma, a autora define o que, segundo ela, seria o "campo da diplomacia": quando representantes nacionais se encontram, seja em um contexto bilateral ou multilateral, o Estado não é mais o campo de poder estruturante e dominante da vida social. Ao invés disso, segundo a autora, existe um campo distinto onde 
esses encontros acontecem e que estruturam suas posições. Lutas particulares emergiriam neste campo da diplomacia quando representantes nacionais se encontram, lutas que, porém, são relativamente autônomas em relação às lutas internas dos Estados.

Neste contexto, a autora define "diplomacia" como a gestão de relações entre Estados soberanos. A diplomacia, portanto, se desenvolveria em um campo específico, no campo da diplomacia, diferente dos campos dos Estados nacionais, porém estruturado por e estruturante destes campos representados pelos Estados nacionais. De acordo com esta linha de pensamento, Bigo (2011) argumenta que este campo (que o autor prefere denominar de "campo transnacional") existe apenas através dos campos nacionais e não como um "nível superior", com sua própria personalidade e características. O que existem são campos sociais locais com relações estendidas para além das fronteiras nacionais.

O que os autores nos sugerem é que a noção de campo de Bourdieu seja extrapolada para além dos limites e fronteiras dos Estados nacionais. ${ }^{4}$ A partir dessa ideia, Bigo e Adler-Nissen descrevem características diferentes deste campo de relações entre Estados, características que, ao nosso olhar, se complementam. Por isso, fizemos o trabalho de definir este espaço de ação internacional dos Estados a partir das definições complementares destes dois autores. Esta é uma análise que parte dos trabalhos de Bigo e Adler-Nissen, contudo, devido ao seu produto representar uma intersecção entre os trabalhos dos dois autores, não chamaremos este campo que estamos definindo nem de "campo da diplomacia" (como em Adler-Nissen), nem de "campo transnacional" (como em Bigo), e sim de "campo das relações internacionais".

Esse campo pode ser pensado em analogia à ideia de Estado como metacampo, ou seja, como um campo transversal aos campos sociais que dele participam, um campo estruturante e estruturado por estes campos sociais e suas relações. Assim, concebemos o campo das relações internacionais como um metacampo: transversal aos Estados que participam dele, um campo estruturante e ao mesmo tempo estruturado por estes Estados e suas relações.

O campo das relações internacionais é o espaço de interação entre Estados. Esta interação acontece em diversos âmbitos, através de diversos agentes que atuam nos campos sociais locais com relações estendidas para além das fronteiras nacionais como, por exemplo, o campo das finanças globais, o das leis internacio-

4 Outros autores, como Sapiro (2013), Dezalay e Garth (2002) e Siméant (2015), também apontam em seus trabalhos para a necessidade de incorporar à noção de campo um aspecto que vá além das análises de âmbito local das relações sociais. 
nais, o da guerra, o da produção científica acadêmica, o das religiões etc. Estes campos se relacionam entre si e possuem ao menos um ponto em comum, a relação entre eles através dos campos do poder locais, que disputam o monopólio do controle dos diversos Estados.

É neste ponto que se encontra o campo dos diplomatas. O campo dos diplomatas está presente, mesmo que não exclusivamente, na relação entre o aparato político-burocrático dos Estados com os outros campos de interação entre os Estados e com o metacampo das relações internacionais. Enquanto esses campos vão se desenvolvendo de maneira relativamente autônoma, em suas relações eles normalmente contam com ações do campo dos diplomatas, ou seja, possuem neles a ação de agentes responsáveis pela gestão oficializada das relações político-burocráticas entre Estados nacionais, reconhecidas e legitimadas socialmente.

No campo das relações internacionais, os campos dos diplomatas de cada Estado são apenas mais um dos campos sociais que nele atuam, porém, diferentemente dos outros campos, os campos dos diplomatas são aqueles que possuem a legitimidade reconhecida de representação e gestão dos "interesses do Estado", portanto, são os campos que estão presentes, mais ou menos intensamente, nas ações dos outros campos de interação entre Estados. Consequentemente, as ações dos campos dos diplomatas ajudam a estruturar o que acontece nos outros campos de interação entre Estados, ao mesmo tempo em que são estruturados por eles. Existem também ações do campo das relações internacionais que se desenvolvem à margem de qualquer relação com o campo dos diplomatas como, por exemplo, as ações de organizações criminosas internacionais que funcionam simbolicamente em oposição ao Estado, por isso caracterizadas como "criminosas".

Nesse ponto, é importante entender como os universos nacional e internacional se conectam na dinâmica de ação do campo das relações internacionais. Esta conexão acontece a partir da ação de agentes que funcionam como verdadeiros tradutores de valores internacionais em nacionais e vice-versa. Esses agentes praticam importação e exportação de capital simbólico, usados internamente no campo de disputa em que atuam, interferindo na dinâmica de funcionamento dos Estados, no campo de poder nacional e, ao mesmo tempo, no campo das relações internacionais. São agentes que praticam papel duplo e sabem jogar os diferentes jogos, nacionais e internacionais. Essa ideia sustenta o conceito de "circulação internacional de ideias", a qual nos remete à existência de um complexo movimento de importação e exportação de valores e concepções de Estado que circulam entre campos do poder local. Essa dinâmica é análoga à dinâmica dos campos: agentes 
em constante disputa pelo domínio simbólico do campo, nesse caso, o campo das relações internacionais.

As maneiras pelas quais os Estados são conduzidos são também o produto dessas disputas em âmbito internacional. Por se tratarem de concepções de Estado criadas em contextos sócio-histórico-material-cultural específicos, para serem importadas e exportadas com sucesso, pressupõem que existam homologias estruturais entre a origem e o destino das ideias exportadas/importadas, assim como possíveis adaptações a serem feitas em relação à ideia importada. Por isso, esta circulação internacional de ideias possui dois aspectos principais: as adaptações de contexto do importador em relação à coisa importada e as homologias estruturais existentes entre importadores e exportadores. Estes dois aspectos são produtos da ação de agentes que funcionam como "pontes" entre as realidades importadoras e importadas, entre as realidades exportadoras e exportadas. Para que essas homologias estruturais existam, assim como para que essas adaptações de contexto sejam feitas, é necessária a existência atuante de agentes que as executem. Estes agentes as fazem em um contexto de disputa interna de seus próprios campos, nas quais a importação do capital social se torna fonte de recursos reconvertida em capital simbólico para uso nas disputas internas ao campo ${ }^{5}$.

Alguns campos que compõem o aparato político-burocrático dos Estados nacionais, como o campo dos diplomatas, são chaves para entender um dos processos que denotam a conexão entre a lógica nacional e internacional: o processo de legitimação simbólica de profissionais da política através da conversão a valores do campo das relações internacionais. Por exemplo, a formação de redes internacionais de lógicas jurídicas, lógicas de segurança militar, lógicas de seguridade social, lógicas de funcionamento de mercados etc. Estas lógicas são muitas vezes criadas pela hibridização internacional da burocracia do Estado através da ação profissional de agentes públicos e privados, como a atuação dos agentes dos poderes executivo (como os diplomatas) e do poder judiciário (como magistrados e advogados), assim como agentes do mercado (como executivos e empresários). Esse processo está fazendo, por exemplo, com que políticos profissionais que focam em ações apenas internas aos Estados fiquem para trás nas disputas do campo do poder.

5 Existem trabalhos que descrevem e analisam a atuação desses agentes. Um dos mais completos é Dezalay e Garth (2002), sobre os agentes do direito e da economia em alguns Estados latino-americanos nos anos da década de 1990, entre eles o Brasil. Outro trabalho, mais específico, sobre a atuação de agentes ligados a movimentos associativistas de magistrados brasileiros pode ser visto em Targa (2010). 
De acordo com as teorias das Relações Internacionais, as fontes de poder dos Estados passam pelas suas dimensões estruturais, definidas pelo seu poderio militar, tamanho da economia, posição geopolítica, expertise de negociação, atratividades culturais entre outros. Tendo em mente a perspectiva de análise bourdiesiana, partiríamos da ideia de que os agentes do campo das relações internacionais se mobilizam em torno do acúmulo de capitais que vão compor o capital simbólico do campo das relações internacionais e, consequentemente, determinar a hierarquia desse campo. Estes capitais podem ser de tipo militar, econômico, territorial, diplomático e cultural. Todos esses capitais seriam fontes de reconversão para formarem o que podemos chamar de capital simbólico internacional. Isso significaria dizer que estes capitais são aceitos e valorizados pelos participantes do “jogo jogado” no campo das relações internacionais, portanto, são características legitimadas de poder nesse campo.

Contudo, esse trabalho de identificação do capital simbólico do campo das relações internacionais precisa passar por um processo maior de análise teórica e, principalmente, empírica. Para entender como esse processo de legitimação e reconversão dos capitais acontece, deve-se examinar os microprocessos ao longo do tempo que legitimam os poderes e contribuem para fazer as ordens sócio-históricas parecerem inevitáveis e naturais. Por isso, a análise do campo das relações internacionais deve passar pelo estudo de sua gênese e formação, que passa por estudos sobre as relações historicamente construídas entre os campos de poder locais desde, por exemplo, suas relações de colonizações e fluxos econômicos mercantis até chegar nas ações contemporâneas das mídias internacionais, ONGs e cortes internacionais de justiça. Aliás, esses últimos são importantes agentes que nas últimas décadas se inseriram definitivamente no campo das relações internacionais ao ponto de conseguirem mudar as regras e desafiar as estruturas historicamente consolidadas do campo.

Contudo, partimos do princípio de que o campo das relações internacionais, assim como o metacampo do Estado, geralmente reproduz desigualdades sem exercer violência física aparente, ou seja, através de violência simbólica. Isso se reflete na atuação da produção de trabalhos acadêmicos que são parte integrante desta reprodução de violência simbólica internacional, como nos deixa claro o conceito de circulação internacional das ideias, visto anteriormente. As pesquisas e atuações de agentes do campo acadêmico muitas vezes reproduzem essa violência simbólica na medida em que, de maneira implícita ou explicita, se tornam instrumentos das disputas do campo das relações internacionais, ajudando a manter ou transformar uma determinada organização hierárquica global específica. 


\section{CONCLUSÃO}

Na pesquisa da qual este artigo é uma parte, entre outros objetivos específicos, procuramos dar os primeiros passos no sentido do entendimento da maneira pela qual se apresenta um pressuposto espaço social internacionalizado, começar a definir suas características e, principalmente, lançar reflexão sobre a influência que este possui sobre o campo dos diplomatas. Para isso, retomamos a ideia de Siméant (2015) quando questiona o fato de uma disciplina, as Relações Internacionais, reivindicar o monopólio da interpretação sobre "o internacional". A autora propõe a não diferenciação entre a ciência social que trata sobre "o internacional" $\mathrm{e}$ "o local". O objetivo de Siméant é mostrar que as mesmas ferramentas de pesquisa que tratam das relações sociais numa escala local também podem ser usadas para analisar as relações sociais em escala internacional. Podemos dizer que essa ideia está presente no sentido de se fazer uma "sociologia das relações internacionais". Trata-se de adotarmos metodologias de pesquisa que não façam diferenciação entre análises e práticas sociais realizadas em escala nacional e internacional, ou seja, trata-se de entendermos as conexões entre os jogos jogados pelos agentes dos campos em âmbito local e global ao mesmo tempo, partindo do princípio de que estes jogos não são ações limitadas por fronteiras artificialmente estabelecidas por análises teóricas que não conseguem enxergar suas conexões.

Uma das maneiras de compreender a lógica de funcionamento de um campo é procurar entender as características de seu capital simbólico próprio. Neste artigo, para entender preliminarmente o que corresponderia ao capital simbólico do campo das relações internacionais, recorremos à produção de conhecimento de teorias da disciplina das Relações Internacionais. Contudo, este trabalho de identificação do capital simbólico do campo das relações internacionais precisa passar por um processo mais exausitivo de pesquisa, tanto teórica quanto, principalmente, empírica.

Este texto não se propõe a fazer um debate crítico sobre as teorias e pesquisas realizadas, hoje, na disciplina de Relações Internacionais. Embora entendamos ser importante nos inserirmos em uma agenda de pesquisa de sociologia da ciência aplicada à produção de conhecimento das Relações Internacionais, esse esforço não coube nos objetivos deste trabalho. Contudo, se faz fundamental pontuar que, pela perspectiva bourdiesiana, o Estado não pode ser um "ator racional" detentor do "interesse nacional". É um metacampo, produtor do metacapital estatal em constante disputa por agentes de diferentes campos sociais que formam o Estado, como já descrito anteriormente. Grande parte das pesquisas tradicionalmente vinculadas à disciplina de Relações Internacionais, sobretudo as que compõem 
a parte hegemônica da disciplina, rejeita a ideia de que o Estado não possa ser considerado um ator. Entendemos que a maneira com que se conceitua o Estado é determinante para a forma com que se analisa as relações sociais internacionalizadas.

Com a perspectiva sociológica bourdiesiana, compreendendo o Estado a partir da noção de campo, passamos a ter à disposição das análises sobre "o internacional” um método de pesquisa relacional e multidimensional que versa sobre as dinâmicas de ação que determinam o que é o Estado: conjunto de grupos dirigentes (elites) dominantes e dominados e suas disputas historicamente localizadas. O Estado é feito a partir de lutas, por isso, não é um campo composto por agentes homogêneos e unitários. O Estado não é uma instituição com sentido único, uniforme e singular, mas um campo, ou melhor, um metacampo de luta.

Esse cenário é indicativo de como é negligenciado o entendimento das práticas sociais que emergem, persistem e constroem o comportamento dos agentes, contribuindo para definir sua imaginação e crenças individuais (LEANDER, 2011). Isso se deve, principalmente, à adoção de procedimentos metodológicos de análise das "relações internacionais" que estabelecem uma distinção entre as práticas sociais em âmbito nacional e internacional, criando um deslocamento teórico e artificial entre "o local" e "o global", o qual impede que tenhamos análises mais precisas sobre essas práticas sociais internacionalizadas. A preferência pela metodologia relacional de Bourdieu (que enfatiza o estudo simultâneo da estrutura e do indivíduo) pode fazer o pesquisador fugir de algumas armadilhas que estudos das Relações Internacionais trazem consigo, tais como a essencialização e o ahistoricismo; um falso dualismo entre construtivismo e pesquisa empírica; e uma oposição absoluta entre o coletivo e o individual. As ferramentas de análise campo e habitus, que são tanto sociais quanto individuais, são úteis para os pesquisadores fugirem dessas armadilhas (Bigo, 2011).

Ao mesmo tempo, no que se refere a análises sobre "o internacional", é importante a não universalização de instrumentos de pesquisa, como o próprio conceito de campo ou o de habitus. Como afirmamos anteriormente, esses são instrumentos metodológicos que só existem na imaginação do pesquisador e precisam ser constantemente testados na prática da pesquisa. De acordo com o objeto de análise, os instrumentos devem ser adaptados à realidade pesquisada. Conceitos como violência simbólica, campo e habitus não são ahistóricos, devem ser identificados e especificados. Por isso, estudos feitos a partir da perspectiva sociológica defendida neste artigo pressupõem um preciso e minucioso exame do objeto, com pesquisas empíricas extensas que mobilizem análises de discursos, 
prosopografias, entrevistas, etnografias, análises de dados estatísticos e análises sobre formação histórica dos diferentes tipos de capitais utilizados pelos agentes dos campos estudados.

Embutida na necessidade de maiores estudos sobre o campo das relações internacionais, está a importância em avançarmos sobre os benefícios de pesquisa que a proposta metodológica bourdiesiana apresenta para os atuais debates teóricos da disciplina das Relações Interacionais. Sendo assim, pretendemos neste texto fazer parte de um exercício inicial de sociologia das relações internacionais, assim como propor a abertura de portas para futuras pesquisas.

\section{REFERÊNCIAS BIBLIOGRÁFICAS}

Adler-Nissen, R. On a Field Trip with Bourdieu. International Political Sociology, vol. 5, p. 327-330, 2011.

Balbino, V. R. Diplomata: substantivo comum de dois gêneros - um estudo sobre a presença das mulheres na diplomacia brasileira. Brasília-DF: Fundação Alexandre de Gusmão, 2005.

Batista, D. N. Habitus Diplomático: um estudo do Itamaraty em tempos do regime militar (1964-1985). Tese (Doutorado). Programa de Pós-Graduação em Sociologia da Universidade Federal de Pernambuco, Recife, 2010.

Bigo, D. Pierre Bourdieu and International Relations: Power of Practices, Practices of Power. International Political Sociology, vol. 5, p. 225-258, 2011.

Bourdieu, P. Les conditions sociales de la circulation internationale des idées. Actes de la recherche en sciences sociales, vol. 5, p. 3-8, 2002.

"Trabalhos e projetos". In: Ortiz, Renato (Org.), A sociologia de Pierre Bourdieu. São Paulo: Olho d’Água, 2003b.

. Razões práticas: Sobre a teoria da ação. Campinas-SP: Papirus, 2011a.

. Homo academicus. Florianópolis: Editora da UFSC, $2011 \mathrm{~b}$.

. Sobre o Estado: Curso no Collège de France 1989-1992. São Paulo: Companhia das Letras, 2014.

Bourdieu, P. E Wacquant, L. Neoliberal Newspeak: Notes on the New Planetary Vulgate. Radical Philosophy, vol. 105, p. 2-5, 2001.

Cervo, A. e Bueno, C. História da Política Exterior do Brasil. Brasília: Editora UnB, 2002.

Delazay, Y. E Garth, B. The Internationalization of Palace Wars: Lawyers, Economists, and the Contest to Transform Latin American States. Chicago: The University of Chicago Press, 2002. 
FARIA, C. A. P. Opinião pública e política externa: insulamento, politização e reforma na produção da política exterior do Brasil. Revista Brasileira de Política Internacional, São Paulo, vol. 51, n. 2, p. 80-97, 2008.

Figueira, A. C. R. Mudando de rumo: um debate acerca do padrão decisório em política externa no Brasil. $7^{\circ}$ Encontro da ABCP, Recife-PE, 2010 .

. Rupturas e continuidades no padrão organizacional e decisório do Ministério das Relações Exteriores. Revista Brasileira de Política Internacional, São Paulo, vol. 53 , n. 2, p. 5-22, $2010 b$.

Gово, K. O Ministério das Relações Exteriores pelos seus atores: uma análise sobre o insulamento burocrático. $34^{\circ}$ Encontro Anual da Associação Nacional de Pós-Graduação e Pesquisa em Ciências Sociais, Caxambu-MG, 2010.

Noblesse d'État: do campo ao habitus da diplomacia brasileira. Tese (Doutorado). Instituto de Filosofia e Ciencias Humanas da Universidade Estadual de Campinas, Campinas-SP, 2016.

Góes Filho, P. O Clube das Nações: a missão do Brasil na ONU e o mundo da diplomacia parlamentar. Rio de Janeiro: Relume-Dumará, 2003.

GRÜN, R. A vingança do baixo clero: o desafio ao "PiG" e o conflito cultural no tratamento da crise financeira. $36^{\circ}$ Encontro Anual da Associação Nacional de Pós-Graduação e Pesquisa em Ciências Sociais, Águas de Lindóia-SP, 2012.

Leander, A. The Promises, Problems, and Potentials of a Bourdieu-Inspired Staging of International Relations. International Political Sociology, vol. 5, p. 294-313, 2011.

Lima, V. L. A. R. (2005). A inserção do negro na carreira de diplomata: ação afirmativa para o Instituto Rio Branco. Dissertação (Mestrado). Programa de Pós-graduação em Sociologia e Antropologia do Instituto de Filosofia e Ciências Sociais da Universidade Federal do Rio de Janeiro, Rio de Janeiro, RJ, 2005.

MERAND. F. Les institutionnalistes (américains) devraient-ils lire les sociologues (français)?. Politique européenne, n. 25, p. 23-51, 2008.

Mıунмото, S. O estudo das relações internacionais no Brasil: o estado da arte. Revista de Sociologia e Política, n. 12, pp. 83-98, junho 1999.

Monteiro, M. M. À sombra do Barão: Por uma sociologia da carreira diplomática brasileira. Dissertação (Mestrado). Faculdade de Filosofia, Letras e Ciências Humanas da Universidade de São Paulo, São Paulo, SP, 2007.

Moura, C. P. Herança e Metamorfose: a Construção Social de dois Rio Branco. Estudos Históricos, v. 14, n. 25, p. 81-102, 2000.

O inglês, o parentesco e o elitismo na casa de Rio Branco. Cena Internacional, ano 8, n. 1, p. 20-34, 2006. 
O Instituto Rio Branco e a diplomacia brasileira: um estudo de carreira e socialização. Rio de Janeiro: Editora FGV, 2007.

Neves, J. A. C. O Papel do Legislativo nas Negociações do Mercosul e da ALCA. Contexto Internacional, vol. 25, n. 1, p. 103-138, janeiro/junho 2003.

Oliveira, R. R. O Congresso Nacional e a Política Externa Brasileira. Posicionamento dos senadores frente as negociações para a formação da ALCA (1994-2005). Dissertação (Mestrado). Programa de Pós-Graduação em História da Universidade de Brasília, Brasília-DF, 2011.

Oliveira, A. P. C. Diplomatas Negros(as): Ação afirmativa no Instituto Rio Branco e Trajetória de Diplomatas (ex-bolsistas). Dissertação (Mestrado). Programa Multidisciplinar de Pós-Graduação em Estudos Étnicos e Africanos da Universidade Federal da Bahia, Salvador, BA, 2011.

Pouponneau, F. La politique française de non-prolifération nucléaire: de la division du travail diplomatique. P.I.E. Peter Lang: Bruxelles, 2015.

SABINE, S. Avons-nous besoin d'une sociologie des relations internationales pour analyser l’intégration européenne ?, Politique européenne, n. 25, p. 193-216, 2008.

SALES, C. R. Relações Internacionais e política externa do Brasil nos governos FHC e Lula. Dissertação (Mestrado). Programa de Pós-Graduação em Ciência Política da Universidade Estadual de Campinas, Campinas-SP, 2007.

SAPIRO, G. Le champ est-il national? La théorie de la différenciation sociale au prisme de l'histoire globale, Actes de la recherche en sciences sociales, n. 200, p. 70-85, 2013. Silva, C. A. V. O vestibular para embaixador e os quartos-secretários: estudo sobre o concurso de admissão à carreira diplomática. Dissertação (Mestrado em Diplomacia). Instituto Rio Branco, Brasília, DF, 2005.

SimEAnT, J. (Org.). Guide de l'enquête globale en sciences sociales. Paris: CNRS Editions, 2015.

TARGA, L. G. A politização do direito na magistratura: ativismo jurídico via associativismo de juízes, uma análise da AJD e da militância pelos direitos humanos. Dissertação (Mestrado). Programa de Pós-Graduação em Ciência Política da Universidade Federal de São Carlos, São Carlos-SP, 2010.

Tomass, L. M. Diferença e igualdade entre Estados: uma etnografia da precedência nas relações diplomáticas. Dissertação (Mestrado). Programa de Pós-Graduação em Antropologia Social da Universidade de Brasília, Brasília, DF, 2001.

WEBER, M. Economia e sociedade: fundamentos da sociologia compreensiva. Brasília, DF: Editora Universidade de Brasília; São Paulo: Imprensa Oficial do Estado de São Paulo, 1999. 